\title{
Pelaksanaan Kebijakan Akreditasi PAUD
}

\author{
Irjus Indrawan \\ FIAI, Universitas Islam Indragiri
}

\begin{abstract}
ABSTRAK
Pendidikan anak usia dini adalah suatu upaya pembinaan yang ditujukan kepada anak sampai dengan usia enam tahun yang dilakukan melalui pemberian rangsangan pendidikan untuk membantu pertumbuhan dan perkembangan jasmani dan rohani agar anak memiliki kesiapan dalam memasuki pendidikan lebih lanjut. Untuk mendapatkan satuan PAUD yang bermutu maka perlu di manajemen secara baik dan untuk mengetahui sejauh mana mutu PAUD maka harus dilakukan akreditasi. Akreditasi sangat penting karena peningkatan mutu atau kualitas pendidikan. PAUD yang bermutu diharapkan menghasilkan generasi masa depan yang berkulitas.
\end{abstract}

Kata Kunci: kebijakan, akreditasi, PAUD

\begin{abstract}
Early childhood education is a coaching effort for children (0-6 years old) by providing education to grow and develop students' physical and spiritual, so they are able to step forwards to the next level of education. Having a qualified institution, there should be well-managed and be accredited. Accreditation is crucial for the institutional quality. The qualified institution is greatly expected to creat qualified generation in the future.
\end{abstract}

Keywords: Policies, Accreditation, Early Childhood Education

Corresponding Author:

Irjus Indrawan

Email address: iirjus@yahoo.com

\section{PENDAHULUAN}

Pada UU RI No.20/2003 Pasal 4 ayat 6 menyatakan bahwa pendidikan diselenggarakan dengan memberdayakan semua komponen masyarakat melalui peran serta dalam penyelenggaraan dan pengendalian mutu layanan pendidikan. Dengan demikian, selain melibatkan seluruh komponen masyarakat dalam kegiatan pendidikan nasional, mutu pendidikan dijadikan sebagai salah satu kebijakan pokok Kementerian Pendidikan dan Kebudayaan (Republik Indonesia, 2003).

Perkembangan dan pertumbuhan lembaga PAUD berkembang pesat dari zaman ke zaman hal ini dapat dilihat dari kuantitas PAUD yang semakin banyak sejak dari kota hingga sampai pelosok desa. Pertumbuhan PAUD disebabkan banyak faktor, faktor yang sangat mencolok karena terbukanya media informasi serta kesibukkan orangtua bekerja yang mengharuskan memasukkan anak mereka ke 
lembaga pendidikan anak usia dini. Sehingga anak mendapatkan pendidikan yang lebih baik dilembaga sesuai dengap tahap usia dan perkembangan anak.

Pada UU RI No.20/2003 Pasal 4 ayat 6 menyatakan bahwa pendidikan diselenggarakan dengan memberdayakan semua komponen masyarakat melalui peran serta dalam penyelenggaraan dan pengendalian mutu layanan pendidikan. Dengan demikian, selain melibatkan seluruh komponen masyarakat dalam kegiatan pendidikan nasional, mutu pendidikan dijadikan sebagai salah satu kebijakan pokok Kementerian Pendidikan dan Kebudayaan (Republik Indonesia, 2003).

Anak usia dini adalah anak yang baru dilahirkan sampai usia 6 tahun. Usia ini merupakan usia yang sangat menentukan dalam pembentukan karakter dan kepribadian anak (Nurani \& Sujiono, 2009, hal. 7). Usia dini merupakan usia di mana anak mengalami pertumbuhan dan perkembangan yang pesat. Dalam undangundang No. 20 Tahun 2003 tentang sistem pendidikan nasional Bab I Pasal 1 ayat 14 dinyatakan bahwa pendidikan anak usia dini adalah suatu upaya pembinaan yang ditujukan kepada anak sejak lahir sampai dengan usia enam tahun yang dilakukan melalui pemberian rangsangan pendidikan untuk membantu pertumbuhan dan perkembangan jasmani dan rohani agar anak memiliki kesiapan dalam memasuki pendidikan lebih lanjut (Republik Indonesia, 2003).

Tujuan dari pendidikan anak usia dini adalah kesiapan anak memasuki pendidikan lebih lanjut, mengurangi angka mengulang kelas, mengurangi angka putus sekolah (DO), mempercepat pencapaian wajib belajar pendidikan dasar 9 tahun, menyelamatkan anak dari kelalaian didikan wanita karir dan ibu pendidikan rendah, meningkatkan mutu pendidikan, mengurangi angka buta huruf muda, memperbaiki derajat kesehatan dan gizi anak usia dini, meningkatkan Indeks Pembangunan Manusia (IPM) (Suyadi \& Ulfah, 2013, hal. 20).

Setiap warga Negara Indonesia berhak memperoleh pendidikan yang bermutu. Sehingga penyelenggara pendidikan haruslah memiliki program kelayakan sesuai dengan Standar Badan Akreditasi Nasional PAUD dan PNF. Manfaat dari akreditasi ini agar dapat menjadi acuan dari upaya peningkatan mutu pendidikan, terlaksananya (visi, misi, tujuan) program sekolah, meningkatkan daya saing mutu pendidikan tingkat Kabupaten/Kota, Nasional, regional bahkan Internasional. Akreditasi juga berfungsi untuk memudahkan mengidentifikasi terlaksananya bantuan pemerintah, donatur, untuk meningkatkan dukungan dari pemerintah, masyarakat, maupun sektor swasta dalam hal bantuan moral, tenaga, serta dana.

Akreditasi lembaga PAUD dan PNF merupakan suatu kegiatan penilaian yang dilakukan oleh badan yang berwenang untuk menentukan sebuah kelayakan program baik dalam pendidikan formal maupun nonformal sesuai dengan kriteria yang sudah ditentukan, yang dilakukan secara objektif, adil, transparan, dan komprehensif dengan menggunakan Instrumen Penilaian Akreditasi BAN PAUD dan PNF yang mengacu kepada Standar Nasional Pendidikan. Fungsi akreditasi sebagai perlindungan sosial kepada masyarakat dalam jaminan kualitas pendidikan juga 
sebagai Qualicy Assuranci yaitu akreditasi harus mengarahkan lembaga untuk menjaga dan meningkatkan mutu pendidikan (Dahliani, 2019). Fokus Akreditasi Ban Paud dan Pnf adalah untuk kualitas PAUD terdiri dari TK, RA, BA, KB, SPS dan TPA. Hasil akhir dari penilaian akreditasi dalam bentuk huruf ( $A=$ Amat Baik), $(B=B a i k),(C=C u k u p)$, dan (TT=Tidak Terakreditasi).

\section{HASIL DAN PEMBAHASAN}

\section{Kebijakan Akreditasi PAUD}

Undang-Undang Sistem Pendidikan Nasional pada Bab I, Pasal 1, dan ayat 32 yang menegaskan bahwa akreditasi adalah kegiatan penilaian kelayakan program dalam satuan pendidikan berdasarkan kriteria yang telah ditetapkan. Selanjutnya, pasal 60 (1) menyatakan, "Akreditasi dilakukan untuk menentukan kelayakan program dan satuan pendidikan pada jalur pendidikan formal dan nonformal pada setiap jenjang dan jenis pendidikan." Kemudian ayat (2); "Akreditasi terhadap program dan satuan pendidikan dilakukan oleh pemerintah dan/atau lembaga mandiri yang berwenang sebagai bentuk akuntabilitas publik." Untuk menjamin bahwa kualitas pendidikan sesuai dengan standar pelayanan minimal atau kriteria lain yang ditentukan oleh pemerintah, maka pemerintah melakukannya melalui akreditasi.

Akreditasi sebagai bagian dari kewajiban pemerintah untuk menentukan apakah satuan pendidikan tersebut layak untuk diakses masyarakat. Hal ini penting agar masyarakat tidak salah memilih lembaga yang berkualitas. Kondisi empiris saat ini menunjukkan bahwa banyaknya lembaga pendidikan anak usia dini yang bergerak ke arah industrialisasi pendidikan dan lebih menekankan pada keuntungan. Bahkan ada juga yang meninggalkan jati diri bangsa. Sebagian lagi hanya mengejar kemampuan tertentu sesuai permintaan pasar.

Akreditasi menjadi mekanisme yang efektif bagi pemerintah untuk memastikan layanan pendidikan yang ada di masyarakat sesuai dengan kriteria yang ditentukan. Sehingga untuk satuan PAUD akreditasi bukanlah bersifat sukarela, tetapi kewajiban. Hal penting dilakukan agar masyarakat terlindungi dari para penyelenggara pendidikan yang sifatnya hanya mementingkan keuntungan semata. BAN PAUD DAN PNF sebagai lembaga mandiri yang diberikan kewenangan pemerintah untuk mengakreditasi satuan PAUD dan PNF mulai 2019 terus-menerus membenahi proses akreditasi. Perbaikan dilakukan mulai dari penyediaan instrumen akreditasi yang pada awalnya dianggap menilai unsur compliance disempurnakan agar dapat menilai performance, peningkatan kompetensi asesor yang bertugas, sistem aplikasi akreditasi termasuk menyiapkan dashboard monitoring, serta mekanisme akreditasi yang melibatkan stakeholder lainnya untuk menjamin data pendidikan terintegrasi dan valid dalam satu data Indonesia. Hal ini dilakukan dalam rangka mendukung program pemerintah, yakni menyediakan informasi bagi masyarakat untuk memilih layanan pendidikan anak usia dini yang berkualitas. Apa yang telah dilakukan BAN PAUD DAN PNF dalam rangka mendukung peran 
pemerintah untuk membantu keluarga membuat pilihan yang tepat ketika mencari layanan PAUD (Yuliantina).

Kebijakan akreditasi PAUD berdasarkan dari landasan-landasan hukum diantaranya adalah (https):

a) Undang-Undang Dasar Negara Republik Indonesia Tahun 1945 mengamanatkan Pemerintah mengusahakan dan menyelenggarakan satu sistem pendidikan nasional yang meningkatkan keimanan dan ketakwaan kepada Tuhan Yang Maha Esa serta akhlak mulia dalam rangka mencerdaskan kehidupan bangsa yang diatur dengan undang-undang; bahwa sistem pendidikan nasional harus mampu menjamin pemerataan kesempatan pendidikan, peningkatan mutu serta relevansi dan efisiensi manajemen pendidikan untuk menghadapi tantangan sesuai dengan tuntutan perubahan kehidupan lokal, nasional, dan global sehingga perlu Kebijakan dan Mekanisme Akreditasi PAUD dan PNF Tahun 2018 | 4 dilakukan pembaharuan pendidikan secara terencana, terarah, dan berkesinambungan;

b) Undang-Undang Republik Indonesia Nomor 20 Tahun 2003 pasal 60 ayat (1) akreditasi dilakukan untuk menentukan kelayakan program dan satuan pendidikan pada jalur pendidikan formal dan nonformal pada setiap jenjang dan jenis pendidikan berdasarkan kriteria yang bersifat terbuka;

c) Undang-Undang Nomor 23 Tahun 2014 tentang Pemerintahan Daerah, untuk sub urusan akreditasi merupakan kewenangan dari Pemerintah Pusat;

d) Peraturan Pemerintah Republik Indonesia Nomor 32 Tahun 2013 yang melengkapi Peraturan Pemerintah Republik Indonesia Nomor 19 Tahun 2005 tentang Standar Nasional Pendidikan, pasal 86 ayat (1) yang menyatakan bahwa pemerintah melakukan akreditasi pada setiap jenjang dan satuan pendidikan untuk menentukan kelayakan program dan/atau satuan pendidikan;

e) Peraturan Pemerintah Republik Indonesia Nomor 13 Tahun 2015 tentang Perubahan Kedua atas Peraturan Pemerintah Nomor 19 Tahun 2005 tentang Standar Nasional Pendidikan pada pasal 1 ayat (32) menyebutkan bahwa Badan Akreditasi Nasional Pendidikan Anak Usia Dini dan Pendidikan Nonformal yang selanjutnya disebut BAN PAUD dan PNF adalah Badan Evaluasi Mandiri yang menetapkan kelayakan program dan/atau satuan pendidikan anak usia dini dan pendidikan nonformal dengan mengacu pada Standar Nasional Pendidikan;

f) Peraturan Menteri Pendidikan Nasional Republik Indonesia Nomor 63 Tahun 2009 tentang Sistem Penjaminan Mutu Pendidikan yang mewajibkan setiap program dan satuan pendidikan untuk turut dalam akreditasi;

g) Peraturan Menteri Pendidikan dan Kebudayaan Republik Indonesia Nomor 13 Tahun 2018 tentang Badan Akreditasi Nasional Sekolah/Madrasah dan BadanAkreditasi Nasional Pendidikan Anak Usia Dini dan Pendidikan Nonformal;

h) Peraturan Menteri Keuangan Nomor 173/PMK.05/2016 tentang Perubahan atas Peraturan Menteri Keuangan Nomor 168/PMK.05/2015 tentang Mekanisme Pelaksanaan Anggaran Bantuan Pemerintah pada Kementerian Negara/Lembaga; dan 
i) Keputusan Menteri Pendidikan dan Kebudayaan Nomor 011/P/2018 tentang Pengangkatan Anggota Badan Akreditasi Nasional Sekolah/Madrasah dan Badan Akreditasi Nasional Pendidikan Anak Usia Dini dan Pendidikan Nonformal Periode Tahun 2018 - 2022.

\section{Mekanisme Akreditasi PAUD}

Akreditasi adalah suatu kegiatan penilaian kelayakan satuan pendidikan berdasarkan kriteria yang telah ditetapkan untuk memberikan penjaminan mutu pendidikan. Kelayakan dari satuan pendidikan berdasarkan standar nasional pendidikan dan sesuai kriteria yang dilakukan secara obyektif, adil, transparan, dan komprehensif. Standar Nasional Pendidikan menurut PP No.32/2013 yang merupakan perubahan pertama dari PP No.19/2005 tentang Standar Nasional Pendidikan adalah sebagai berikut:

a. Standar Kompetensi Lulusan adalah kriteria mengenai kualifikasi kemampuan lulusan yang mencakup sikap, pengetahuan dan keterampilan;

b. Standar Isi adalah kriteria mengenai ruang lingkup materi dan tingkat kompetensi untuk mencapai Kompetensi lulusan pada jenjang dan jenis pendidikan tertentu

c. Standar Proses adalah kriteria mengenai pelaksanaan pembelajaran pada satu satuan pendidikan untuk mencapai Standar Kompetensi Lulusan

d. Standar Pendidik dan Tenaga Kependidikan adalah kriteria mengenai pendidikan prajabatan dan kelayakan maupun mental, serta pendidikan dalam jabatan;

e. Standar Sarana dan Prasarana adalah kriteria mengenai ruang belajar, tempat berolahraga, tempat beribadah, perpustakaan, laboratorium, bengkel kerja, tempat bermain, tempat berkreasi dan rekreasi serta sumber belajar lain, yang diperlukan untuk menunjang proses pembelajaran, termasuk penggunaan teknologi informasi dan komunikasi

f. Standar Pengelolaan adalah kriteria mengenai perencanaan, pelaksanaan, dan pengawasan kegiatan pendidikan pada tingkat satuan pendidikan, kabupaten/kota, provinsi atau nasional agar tercapai efisiensi dan efektivitas penyelenggaraan pendidikan

g. Standar Pembiayaan adalah kriteria mengenai komponen dan besarnya biaya operasional satuan pendidikan yang berlaku selama satu tahun;

h. Standar Penilaian Pendidikan adalah kriteria mengenai mekanisme, prosedur dan instrumen penilaian hasil belajar peserta didik.

Pelaksanaan akreditasi tidak serta merta bisa begitu saja dilakukan, namun memiliki tahapaan yang harus dilalui. Adapun mekanisme akreditasi PAUD adalah sebagai berikut:

Persyaratan akreditasi

a. Persyaratan umum pengajuan akreditasi PAUD:

1. Mengajukan permohonan akreditasi kepada BAN PAUD dan PNF Provinsi.

2. Memiliki izin penyelenggaraan/izin operasional.

3. Akte pendirian dari notaris atau yang berwenang. 
4. Program akreditasi yang diajukan telah beroperasi minimal 2 tahun.

5. Memiliki NPSN (Nomor Pokok Satuan Pendidikan Nasional)

6. Adanya sarana dan prasarana dengan dibuktikan dengan dokumentasi yang sah (sertifikat kepemilikan tanah dan bangunan/surat perjanjian sewa)

b. Persyaratan khusus pengajuan akreditasi :

1. Jumlah peserta didik minimal 10 anak pada tahun ajaran terakhir.

2. Memiliki Ijazah untuk pendidik. Minimal SLTA/SMA

3. Memiliki minimal 1 (Satu) pendidik yang bersertifikat diklat dasar PAUD.

4. Tahapan akreditasi (klasifikasi permohonan akreditasi, visitasi, validasi dan verifikasi, penetapan hasil akreditasi).

5. EDS PA mengacu pada standar nasional pendidikan untuk melihat kelengkapan dan kebenaran dokumen lembaga (Compliance) yang terintegrasi dengan DAPODIK

6. Visitasi untuk melihat kinerja lembaga (performance) menggunakan instrument penilaian akreditasi (IPA).

Satuan pendidikan pertama kali melakukan pengisian evaluasi diri satuan sebagai pra-syarat akreditasi (EDS-PA) di Sispena. Pendaftaran akreditasi dimulai ketika pesyaratan EDS PA mulai diunggah. Anggota BAN-P atau Sekretariat mulai melakukan penilaian EDS-PA. BAN P menugaskan asesor untuk melakukan visitasi ke satuan pendidikan. BAN P menugaskan asesor melakukan validasi pada satuan pendidikan (asesor visitasi berbeda dengan asesor validasi. Ketua BAN Paud dan PNF sudah menandatangani E-Sertifikat satuan pendidikan dan dapat didownload disispena masing-masing.

a. Visitasi

Visitasi adalah kunjungan ke tempat lembaga yang sudah melewati prosedur pengajuan akreditasi yang dilakukan oleh utusan dari BAN PAUD dan PNF terdiri dari 2 orang asesor. Visitasi dilaksanakan setelah satuan pendidikan mengisi data di Sispena, dan sudah dinilai oleh KPA. Tujuan dari visitasi ini adalah memberikan petunjuk teknis prosedur pelaksanaan Visitasi Satuan PAUD dan PNF yang akan dilakukan oleh Asesor yang ditetapkan oleh BAN PAUD dan PNF. Hasil Yang Diharapkan dalam visitasi ini diperolehnya data dan informasi satuan pendidikan yang telah divisitasi untuk dilanjutkan ke tahapan Validasi dan Verifikasi.

Saat visitasi berlangsung ada prosedur pembukaan (opening meeting)sampai dengan penutupan (closing meeting). Visitasi dilaksanakan satu hari pada satu lembaga pendidikan. Pada saat visitasi asesor harus mengetahui kode etik dan teknik verifikasi data seperti observasi dikelas, diluar kelas, melakukan wawancara dan melihat bukti fisik dokumen yang sudah dikirim di Sispena. Setelah data didapatkan sesuai dengan IPA (Instrumen Penilaian Akreditasi) asesor mengisi penilaian di sispena sendiri. Diharapkan asesor dapat mentuntaskan visitasi penilaian dalam satu hari tersebut, dikirim langsung 
sehingga terlihat ketuntasan pada lembaga yang diakreditasi. Hasil dari visitasi disampaikan pada berita acara dibacakan bersama dan diserahkan pada lembaga sebagai bukti sudah melakukan visitasi. Kegiatan visitasi akreditasi dilaksanakan pada: Hari dan Tanggal: Berdasarkan jadwal kegiatan BAN PAUD dan PNF Provinsi. Tempat yang dilakukan di Lembaga tersebut baik di Kabupaten/Kota setempat. Visitasi dilaksanakan dengan satu lembaga satu hari tidak boleh dua lembaga dalam satu hari.

\section{b. Tata Cara Akreditasi PAUD dan PNF}

Asesor adalah orang yang melakukan kegiatan visitasi, berhak untuk melihat, menguji atau menilai lembaga sesuai dengan standar Badan Akreditasi Nasional BAN Paud dan PNF. Dalam melakukan penilaian saat visitasi asesor WAJIB melakukan observasi terhadap: seluruh proses kegiatan pembelajaran sebelum dimulai sampai seluruh kegiatan di satuan berakhir; dan pengelolaan kelembagaan.

Setelah asesor mengobservasi adapun yang harus dilakukan adalah:

a. Asesor mengisi format Instrumen Penilaian Akreditasi dengan cara memberi tanda centang $(\sqrt{ })$ pada masing-masing kolom sesuai dengan petunjuk pada masing-masing butir; 1 . Asesor wajib memberikan tanda centang $(\sqrt{ })$ pada kolom YA atau TIDAK berdasarkan pengamatan/wawancara langsung kepada beberapa peserta didik (secara acak), pendidik, tenaga kependidikan dan pihak-pihak yang terkait, serta pemeriksaan data/dokumen yang ada. Bukti tersebut dilampirkan dalam bentuk video/foto/dokumen lainnya;

b. Lampiran bukti dalam format video yang disepakati oleh asesor A dan B diunggah ke dalam akun google drive kelompok;

c. Asesor A dan Asesor B berdiskusi menentukan nilai kelompok yang diisi oleh asesor A;

d. Asesor visitasi melaksanakan visitasi 30 menit sebelum KBM sampai dengan kegiatan di Satuan berakhir;

e. Asesor visitasi menilai indikator performance; Panduan Penilaian Akreditasi Satuan Pendidikan PAUD dan PNF.

f. Asesor visitasi mengecek kebenaran indikator compliance Asesi pada EDSPA;

g. Asesor visitasi melakukan penelusuran dengan pendekatan TRIANGULASI;

h. Sumber data berasal dari PTK, orangtua, peserta didik dan lain-lain.

Selanjutnya, Asesor memberikan catatan visitasi (catatan butir dan catatan standar) berdasarkan hasil pengamatan dan wawancara serta bukti yang dilampirkan;

1. Catatan butir

Catatan butir adalah catatan yang dijelaskan setip butirnya sesuai dengan apa yang dilihat dilapangan. Adapun catatan butirnya adalah: 
a) Berisi penjelasan mengapa diberikan nilai YA/TIDAK pada proses visitasi.

b) Merupakan penguatan terhadap Video/foto/dokumen yang diunggah.

c) Dapat pula berupa catatan lainnya hasil observasi, wawancara atau penelusuran bukti dengan berbagai cara.

d) Catatan berupa bukti performance yang ditemukan saat visitasi dalam setiap butirnya baik ditelusuri saat pelaksanaan visitasi, maupun dari dokumen lainnya yang ditemukan (dapat juga kegiatan dilaksanakan bukan pada waktu visitasi, tetapi ditemukan bukti yang valid) 2) Catatan Standar.

e) Berisi catatan hasil penilaian perstandar berdasarkan bukti performance

f) Dicatat dengan menggunakan pola.

2. Capaian-Masalah-Rekomendasi (CMR), dituliskan dalam satu narasi yang utuh sebagai berikut:

a) Capaian merupakan fakta yang ditemukan saat visitasi terkait standar, dapat dari beberapa butir atau seluruh butir pada standar tersebut.

b) Masalah merupakan kendala/tantangan yang ditemukan untuk diatasi oleh satuan baik dalam setiap butir maupun beberapa butir atau seluruh butir standar.

c) Rekomendasi merupakan saran perubahan yang dapat dilakukan oleh satuan untuk mengatasi masalah yang ditemukan dalam pelaksanaan standar tersebut.

d) Catatan menunjukkan performance dari setiap standar.

Asesor visitasi mengisi format Berita Acara Visitasi yang ditandatangani oleh kedua Asesor Visitasi dan Asesi, selanjutnya diunggah di Sispena 2.0; Panduan Penilaian Akreditasi Satuan Pendidikan PAUD dan PNF. Kegiatan visitasi oleh asesor sudah selesai dilakukan, selanjutnya masing-masing asesor mengunggah atau mengupload foto, dokumen, video pada upload lampiran. Rangkaian kegiatan visitasi telah selesai dilakukan.

\section{c. Banding Atas Status Akreditasi}

Banding adalah permintaan dari satuan pendidikan PAUD dan PNF untuk mempertimbangkan kembali keputusan yang merugikan, yang dibuat BAN PAUD dan PNF terkait dengan hasil penilaian status akreditasi PAUD dan PNF. Pengajuan banding dapat dilakukan dengan melampirkan argumentasi berdasarkan capaian delapan standar nasional pendidikan. Pengajuan banding dilakukan dengan mengikuti prosedur sebagaimana disebutkan pada Panduan Pengajuan Banding Akreditasi yang ditetapkan BAN PAUD dan PNF. Adapun permohonan banding dapat diajukan dalam waktu maksimal 30 hari kalender sejak tanggal SK Akreditasi diumumkan di Website BAN PAUD dan PNF (Panduan Akreditasi BAN PAUD dan PNF, 2019). 
Akreditasi lembaga PAUD merupakan suatu kegiatan penilaian yang dilakukan oleh badan yang berwenang untuk menentukan sebuah kelayakan program pendidikan anak usia dini (PAUD) sesuai dengan kriteria yang sudah ditentukan, yang dilakukan secara objektif, adil, transparan, dan komprehensif dengan menggunakan Instrumen Penilaian Akreditasi BAN PAUD dan PNF yang mengacu kepada Standar Nasional Pendidikan.

Akreditasi sangat penting karena peningkatan mutu atau kualitas pendidikan. Pendidikan bermutu diharapkan menghasilkan generasi dan pemimpin masa depan yang berkulitas. Sehingga dengan demikian akan membawa Indonesia ke pintu gerbang kemajuan di segala bidang. Bagi lembaga, akreditasi membantu untuk mengetahui sejauhmana lembaga telah memenuhi kriteria mutu yang sudah ditetapkan pemerintah; sebagai evaluasi terhadap kinerja lembaga, perencanaan jangka pendek dan jangka panjang; sebagai dasar untuk melakukan perbaikan dan peningkatan mutu pendidikan pada masa yang akan datang; dan sebagai bentuk kepatuhan terhadap peraturan pemerintah serta sebagai bagian dari akuntabilitas publik. Akreditasi PAUD penting bagi masyarakat karena hasil akreditasi menggambarkan mutu suatu lembaga. Melalui akreditasi, orang tua juga dapat mengetahui dengan legalitas sebuah lembaga yang telah diakreditasi. Sedangkan bagi pemerintah, akreditasi sangat penting karena merupakan amanah konstitusi. UndangUndang Nomor 20 Tahun 2003 tentang Sistem Pendidikan Nasional (Sisdiknas) secara eksplisit disebutkan pada pasal 60 Ayat 2; "Akreditasi terhadap program dan satuan pendidikan dilakukan oleh Pemerintah dan/atau lembaga mandiri yang berwenang sebagai bentuk akuntabilitas publik."

\section{DAFTAR PUSTAKA}

https:// banpaudpnf.kemdikbud.go.id/upload/downloadcenter/Pedoman \%20Kebijakan\%20dan\%20Mekanisme\%20Akreditasi\%20PAUD\%20 da_1545973435.pdf

Dahliani, A. (2019). Mengintip Kegiatan Akreditasi PAUD. Cimahi.

Nurani, Y., \& Sujiono. (2009). Konsep Dasar Pendidikan Anak Usia Dini. Jakarta: PT. Indeks.

Panduan Akreditasi BAN PAUD dan PNF. (2019). Diambil kembali dari www.banpaudpnf.com Peraturan Pemerintah No. 32 Tentang Standar Nasional Pendidikan. (2013). Jakarta.

Republik Indonesia. (2003). Undang-undang No. 20 Tentang Sistem Pendidikan Nasional. Jakarta: Sekretariat Negara Republik Indonesia.

Suyadi, \& Ulfah, M. (2013). Konsep Dasar PAUD. Bandung: PT. Remaja Rosdakarya.

Yuliantina, I. Pentingnya Akreditasi Satuan PAUD. Diambil kembali dari https:// banpaudpnf.kemdikbud.go.id/berita/pentingnya-akreditasi-satuan-paud 